\title{
The Shared Pleasure Paradigm: A study in an observational birth cohort in South Africa
}

\author{
Anusha Lachman ${ }^{1}$ (D) Esme R. Jordaan ${ }^{2,3} \cdot$ Micky Stern $^{4,5} \cdot$ Kirsten A. Donald $^{6,7} \cdot$ Nadia Hoffman $^{4,5} \cdot$ Marilyn T. Lake $^{6}$. \\ Heather J. Zar ${ }^{6,7} \cdot$ Dana J. H. Niehaus ${ }^{1} \cdot$ Kaija Puura ${ }^{8} \cdot$ Dan J. Stein ${ }^{4,5}$
}

Received: 29 July 2021 / Accepted: 20 December 2021 / Published online: 5 January 2022

(c) The Author(s) 2022

\begin{abstract}
Mother-infant dyads in low- and middle-income countries (LMICs) may be exposed to a range of factors associated with suboptimal development. Optimal infant development is likely supported by synchronicity in the early mother-infant relationship, but limited corroborative research is available in LMICs. The Drakenstein Child Health Study (DCHS) provided an opportunity to study this synchronicity and its associations in South Africa. A South African birth cohort study investigating early-life determinants of child health in a LMIC context provided participants. The Shared Pleasure (SP) paradigm helped assess early mother-infant synchronicity in videos of a sub-set of 291 mother-infant dyads at their 14-week well baby visit. General linear regression models investigated the relationship between selected maternal and infant characteristics and the presence of Shared Pleasure moments. Out of a possible 291 dyads, $82 \%(n=239)$ yielded Shared Pleasure moments. The mean age of mothers was 27 years, while infant sex distribution comprised $54 \%$ females and $46 \%$ males. The shortest single Shared Pleasure moment lasted at least $0.5 \mathrm{~s}$ and the longest $28 \mathrm{~s}$. Shared Pleasure moments were associated with higher gestation age at delivery $(p=0.008)$ and higher infant birth weight $(p=0.006)$, but were not related to mother's mental health and infant health outcomes at 14 weeks. The high frequency of positive Shared Pleasure moments in reciprocal dyadic interactions in this sample suggests that significant disruption in shared pleasure may be present only in extreme cases (e.g. mothers with severe mental disorders). Further work is needed to investigate the mechanisms underlying the associations between early mother-infant synchronicity and better outcomes noted here, and to assess whether SP may serve as a culturally appropriate screen for assessing connectedness.
\end{abstract}

Keywords Shared pleasure $\cdot$ Synchronicity $\cdot$ Mother-infant relationship $\cdot$ Infant development $\cdot$ Low and middle-income country 35

Anusha Lachman

anusha@sun.ac.za

1 Department of Psychiatry, Stellenbosch University, Cape Town, South Africa

2 Biostatistics Unit, South African Medical Research Council, Parow, South Africa

3 Department of Statistics and Population Studies, University of the Western Cape, Cape Town, South Africa

4 South African Medical Research Council Unit On Risk and Resilience in Mental Disorders, Cape Town, South Africa
5 Department of Psychiatry and Neuroscience Institute, University of Cape Town, Cape Town, South Africa

6 Department of Paediatrics and Child Health, Red Cross War Memorial Children's Hospital, University of Cape Town, Cape Town, South Africa

7 South African Medical Research Council Unit On Child and Adolescent Health, Cape Town, South Africa

8 Department of Child Psychiatry, Tampere University and Tampere University Hospital, Tampere, Finland 


\section{Introduction}

Mother-infant dyads in low- and middle-income countries (LMICs) may be exposed to a range of factors associated with suboptimal developmental outcomes. Substantial numbers of perinatal mental health disorders occur in LMICs, particularly in poorer peri-urban and rural areas (Fisher et al. 2012; Brittain et al. 2015). The early social environment fundamentally determines early child development and influences long-term child health outcomes (Maggi et al. 2010; Richter et al. 2020). Risk factors such as socio-economic stressors, poor social support and substance use, perinatal mental health disorders may impact and undermine mothers' capacity to respond optimally to infants' needs (WHO 2018). Adverse conditions like poverty inhibit parents' capacity for providing security and assuring good developmental outcomes, especially for mothers vulnerable to mental health disorders (Patel et al. 2008). Early parent-infant relationships are key contributors to the socio-emotional development of growing children (Wachs et al. 2009; Richter et al. 2017).

Synchronicity within early mother-infant relationships seemingly supports optimal infant development, but there is limited relevant research in LMICs (Leclère et al. 2014). Synchronised behaviours like mutual gaze and gaze following between mothers and infants allegedly create the foundation of early social connectedness and regulation (Brooks and Meltzoff 2013), with positive emotions shared in meaningful relationships contributing social, intellectual and psychological resources (Ramsey and Gentzler 2015). Sharing positive affect in parent-infant interactions fuels the organisation of early infant experiences of socialisation (Feldman 2007), and positive caregiver-child interactions help infants develop socially and emotionally. Demonstrations of affection convey empathy to infants, manage responses to their dependence and model regulatory behaviours, and positive emotional interactions consistently increase mothers' influence on and connectedness to their infants (Santamaria et al. 2020). The WHO's Nurturing Care Framework (2018) highlights bidirectional communication and enjoyable, stimulating care as core to the provision of responsive care within healthy mother-child relationships.

Few studies have explored mother-infant relationships and synchronicity in LMICs (Donald et al. 2019) and few tools for assessing synchronicity have been validated in LMICs (Keller et al. 2018). Most studies in this setting focused on negative infant-caregiver interactions (Murray et al. 1996; Cooper et al. 2002; Christodoulou et al. 2019) with limited work exploring "Shared Pleasure (SP)" (Lachman et al. 2021). The former studies in similar settings in South Africa, reported more negative engagements (less sensitivity, less positive affect, less talking) between depressed mothers and their children and interventions were targeted at identifying and improving these negative interactions. Shared Pleasure is ideally measured in younger infants. During the first two months of life, touch gives way to gaze as a mode of interpersonal relatedness and gaze synchrony becomes the main vehicle for social interactions. (Feldman et al. 1999; Feldman 2007). By three months of age, an infant is seen to be more communicative and socially focused. This includes the emergence of emotions like sadness and joy, as well as social smiling. Younger infants are more likely to engage in direct face interactions as compared to older infants who are able to crawl away, thus limiting spontaneous opportunities for eye contact and positive emotional expressions (Sallquist et al. 2010; Puura et al. 2019).Two months seem to be the age at which mothers smile most automatically at their infants (Puura et al. 2019).

Culture influences a mothers' behaviour towards her infant, and different communitiesmay emphasise different dimensions of interactions with their children. At the same time, it is problematic to assert that all mothers belonging to a particular cultural community behave in the same way. Parenting behaviours may be influenced by a broad range of determinants, including psychological and societal factors. At the same time, reciprocal positive SP interactions involve innate mechanisms, may overlap across different cultures, and can be measured effectively through direct observation in a range of settings.

The Drakenstein Child Health Study (DCHS), an ongoing birth cohort study in South Africa, assesses a range of maternal and infant measures (Stein et al. 2015; Zar et al. 2015). The current study aimed to explore the prevalence of shared pleasure moments in mother-infant dyads, to investigate associations of maternal and infact characteristics with the frequency and occurrence of shared pleasure. We hypothesised that greater SP would be associated with better maternal mental health and early childhood development.

\section{Methods}

\section{Site}

The Drakenstein Child Health Study (DCHS) is a population-based birth cohort study investigating early-life determinants of child health and development (Zar et al. 2015) provides details on the parent study). It is based on a peri-urban, low socio-economic neighbourhood in Paarl outside of Cape Town. Drakenstein is a stable community comprising approximately 200,000 people, and characterised by a high prevalence of health risk factors like depression, childhood trauma and poverty (Donald et al. 2019). 
It is considered representative of peri-urban regions across South Africa with most residents utilising primary public healthcare clinics.

\section{Population}

Pregnant women between 20 and 28 weeks gestation were recruited from a public sector primary healthcare facility in the Drakenstein district, enrolled into the DCHS while attending routine antenatal care, and prospectively followed through childbirth and early childhood. This study included the subset of infants who were seen at the 14-week follow-up visit and had a 6-month developmental assessment.

\section{Measures}

Demographic and clinical (physical and psychological) child measures were assessed. Variables included maternal social and biological risk and protective factors (including maternal education, employment, mental illness and substance use) and an infant neurodevelopmental assessment (Bayley Scales of Infant Toddler Development-BSID-III scale). Video-recorded dyadic interactions between mothers and infants were assessed for SP. Videos with at least $5 \mathrm{~min}$ unobstructed interactional visuals of infant and mother were deemed acceptable. Dyads were videotaped at 14-week well baby follow-up clinic visits.

\section{Video Recordings}

At these 14-week visits, mothers were recorded interacting with their infants for 5-10 min. The video camera was positioned for a full-face view of infants and mothers in profile. A mirror adjacent to the infants' seat included infants' faces and whole bodies, as well as full-face reflections of mothers, in the frame. Mothers played freely with their infants without using toys.

\section{SP Paradigm}

SP in parent-infant interactions-defined as "the parent and the child sharing positive affects in synchrony" (Puura et al. 2002) — was analysed from the first 5 min of the recording, a time span in which interrater reliability is good (Kemppinen et al. 2005). This had to be indicated by synchronised facial expressions like the mouth curving into a smile or laugh during gaze contact. If infants were sleepy or close to feeding, a second video was attempted when they were more alert. Tapes were observed at full speed, tagging all possible sequences of SP. Tagged parts were then reviewed at half speed, registering beginnings and endings of SP sequences per second. SP moments were measured by a single rater (AL) blinded to the history of the mother. Measurement for SP comprised three components: occurrence of an SP moment, total number of SP moments, and duration of the SP moment. AL received training in reliability by KP who developed this SP analysis method. To assess interrater reliability, $10 \%$ of the videos were randomly selected using the random number generator in Excel and were rated independently by two coders (AL and KP). The kappa values for the SP variables used in the analysis, i.e. the occurrence of SP sequences and the mean duration of SP $(<0.5$ or $>0.5 \mathrm{~s}$ ), were 0.79 and 0.46 , respectively. The respective rates of interrater agreement were substantial for occurrence of SP moments and moderate for mean duration of SP157 (McHugh 2012).

\section{Child development: Bayley Scales of Infant and Toddler Development}

The Bayley Scales of Infant and Toddler Development, Third Edition (BSID-III) (Bayley 2006) — a gold-standard observational measure of childhood development from 0 to 42 months - assessed child development at 24 months as part of the DCHS parent study. It has been validated and is considered culturally appropriate for South African application (Rademeyer and Jacklin 2013). It measures development by direct observation across five subscales: cognition, receptive and expressive language, and fine and gross motor development. For this study, the 24-month BSID-III composite cognitive, motor and language scores were generated using BSID-III normative and conversion tables, accounting for gestation at delivery. These scales were measured via direct observation by a trained physiotherapist blinded to the risk factors, and overseen by a paediatric neurologist (Donald et al. 2018). The original DCHS parent study analysis calculated raw and scaled scores using a normal US population, scaled to a mean of 10 and a standard deviation of 3. Poor developmental outcomes were assessed by categorising scores into 'delay' or 'no delay', defined by scoring $\leq 1$ standard deviation below the mean scaled score (using a cut-off of 7). For the current study analysis, composite scores were used and categorised with a score $<85$ indicating a 'delay' which was 1 SD from the mean for the South African population (le Roux et al. 2018).

\section{Maternal measures}

\section{Several aspects of maternal mental health were assessed}

The Edinburgh Postnatal Depression Rating Scale (EPDS) (Cox et al. 1987) is a 10-item self-report measure of recent depressive symptoms. Each item is scored on a frequency scaleranging from 0 to 3 . The total score is obtained by 
summing individual item responses. A higher score indicates stronger depressive symptoms; a cut-off score $\geq 13$ indicates probabledepression. Cronbach's alpha $(\alpha)$ in the larger cohort of 1137 mothers $=0.79$.

The WHO-endorsed Self-Reporting Questionnaire-20 (SRQ-20) (Beuenberg and Orley, 1994) measures psychological distress. Prolifically used locally and internationally, it maintains good reliability and face validity (Harpham et al. 2003) and consists of 20 items assessing non-psychotic symptoms. Individual items are summed to generate a total score. A cut-off score $\geq 8$ can help sort participants into "high risk" versus "low risk" (Harpham et al. 2003). The measure demonstrated adequate reliability $(\alpha=0.82)$.

The Intimate Partner Violence (IPV) Questionnaire is a 12 item inventory adapted from the WHO multi-country study (Jewkes 2002) and the Women's Health Study in Zimbabwe (Shamu et al. 2011) to assess lifetime and recent (past 12 months) exposure to emotional, physical and sexual IPV. Categories are assessed across multiple items measuring frequency and number of acts. Scoring guidelines for the DCHS categorised participants as above or below threshold depending on responses of low (once), mid (more than once) or high (many times) frequency of exposure to violence. Emotional abuse subscale: $\alpha=0.85$; physical abuse subscale: $\alpha=0.86 \&$ sexual abuse subscale: $\alpha=0.83$. Studies in South Africa have used the adapted IPV including in high-risk HIV-positive samples (Donald et al. 2019; Jewkes et al. 2010).

The World Mental Health Life Events Questionnaire (LEQ) is a 17-item tool which assesses exposure to stressful life events during the previous 12 months. The questionnaire used in this study is based on the items used in the South African Stress and Health Study (Myer et al. 2008). A total score is obtained by summing the total number of life events reported during this time frame; higher scores indicate greater exposure to stressful life events, with $\alpha=0.71$.

The Alcohol, Smoking and Substance Involvement Screening Test (ASSIST) (WHO Assist Working Group 2002) was developed by the WHO to detect and manage substance use among people employing primary healthcare services. It assesses substance use and substance-related risk across diverse categories of substances and is widely used in South Africa (van der Westhuizen et al. 2016). Total scores are obtained for each substance by summing individual item responses, with a higher score indicative of greater risk for substance-related health problems. For alcohol use, scores of 0-10 indicated low risk, 11-26 moderate risk, and scores $>26$ a participant's high risk of experiencing severe problems resulting from their current pattern of use and likely dependence (Humeniuk et al. 2010). The alcohol use subscale demonstrated adequate reliability $(\alpha=0.91)$.

\section{Statistical Analysis}

A series of bivariate models were was conducted to test the link between preceding perinatal maternal and infant factors on and SP at $31 \frac{1}{2}$ months. SP was assessed in two metrics: (1) frequency of SP moments [SP Frequency] and (2) occurrence of SP moments (i.e. presence vs absence) [SP Occurrence]. Due to the overdispersion of SP frequency data, negative-binomial regression models were conducted to gauge the potential impact of maternal and infant factors on SP frequency. Logistic regression was used to model SP occurrence regarding maternal and infant factors. Further sensitivity analyses were run to assess whether findings differed according to additional SP metrics which included (3) aggregated duration of SP [SP Sum] or (4) average duration of SP [SP Short-Average], both using negative-binomial regression modelling.

Perinatal maternal mental health factors like perinatal depression (EPDS), lifetime and recent intimate partner violence (IPV), psychological distress (SRQ-20), stressful life events (LEQ) and alcohol use (ASSIST) were measured at antenatal and/or 6-10-week postnatal visits. The maximum score across perinatal visits was used to minimise the amount of missing maternal mental health data in bivariate analyses of each mental health factor and SP. Early infant development was assessed using several continuous composite scales taken at 2 years, including cognition, motor, language, socio-emotional and general adaptive behaviour, each assessed in relation to SP. Additional factors like maternal age at birth, marital status, employment status, education, HIV status, infant sex, gestational age and birth weight were investigated. All models assumed a significance level of 0.05 , and all estimates were presented with $95 \%$ confidence intervals. Analyses were run using SAS (V9.4) and R (R Core Team 2021).

\section{Ethical Considerations}

The DCHS study was approved by the Faculty of Health Sciences Research Ethics Committee, University of Cape Town (401/2009) and Western Cape Provincial Research Committee (2011RP45). An amendment for the inclusion of the Shared Pleasure Analysis was granted (16/12/2016). At enrollment, mothers gave voluntary, written, informed consent in their preferred language (English, Afrikaans or isiXhosa) and were reconsented annually for study involvement. Parents gave consent for children younger than 12 months as per South African National HREC guidelines that extend the parameters for informed consent by parents to include infants specifically under 12 months of age (Department of Health: RSA 2015). All data were anonymised using a study number to code for each mother-infant dyad. 


\section{Results}

\section{Maternal and infant characteristics}

A sample of 291 out of a possible 296 videos of mother-infant dyads was suitable for assessing Shared Pleasure (SP). Infant sex distribution comprised 54\% females and $46 \%$ males. Mothers were young (mean age $=27$ years $(\mathrm{SD}$ 5.9)), mostly unmarried (84\%) and largely had at least a secondary school level education (95\%). Seventy-three percent of mothers were unemployed (see Table 1), and the majority scored below the threshold for depression (63\%) as measured by the EPDS. Seventy-six percent indicated a low risk of psychological distress as measured by the SRQ-20 screen. Most participants $(86 \%)$ reported few $(<5)$ stressful events in the past year.

Table 1 reports on maternal characteristics and mental health measures.

Table 2 reports on infant characteristics and infant BSIDIII composite scores corrected for gestation.

\section{SP moments and their associated factors}

Of the total sample $(\mathrm{N}=291), 239(82 \%)$ maternal-infant dyads experienced SP moments [SP occurrence], displaying a median of 5 (IQR: 1-11) SP moments [SP frequency]. The maximum number of SP moments recorded in a single dyad

Table 1 Maternal characteristics

\begin{tabular}{lll}
\hline Variable & & $n(\%)$ \\
\hline Age at birth (years) & & $27(5.9) *$ \\
Marital status & Married & $47(16 \%)$ \\
& Single/cohabiting & $243(84 \%)$ \\
Education & Primary & $190(65 \%)$ \\
& Secondary & $85(29 \%)$ \\
& Tertiary & $16(6 \%)$ \\
Employment & Employed & $48(16 \%)$ \\
& Unemployed & $243(84 \%)$ \\
HIV status & Infected & $69(24 \%)$ \\
& Negative & $222(76 \%)$ \\
Depression (EPDS) & Below threshold $(<13)$ & $179(63 \%)$ \\
& Above threshold $(\geq 13)$ & $103(37 \%)$ \\
Psychological distress (SRQ- & Low risk $(<8)$ & $213(76 \%)$ \\
20) & High Risk $(\geq 8)$ & $69(24 \%)$ \\
Stressful life events (LEQ) & $<5$ events & $242(86 \%)$ \\
& $\geq 5$ events & $39(14 \%)$ \\
Intimate partner violence (IPV) & & \\
Lifetime (exposure $>12$ months) & & $154(54 \%)$ \\
& Above threshold & $131(46 \%)$ \\
\hline & Below threshold & \\
& &
\end{tabular}

Table 2 Infant characteristics

\begin{tabular}{ll}
\hline Variable & Mean (sd) \\
\hline Sex & \\
Female n (\%) & $136(46 \%)$ \\
Male n (\%) & $155(54 \%)$ \\
Gestational age (weeks) & $38.5(2.7)$ \\
Birth weight (kg) & $3.1(0.6)$ \\
BSID-111 composite scores & \\
Motor & $91.8(12.1)$ \\
Cognition & $85.3(10)$ \\
Language & $83.9(11.8)$ \\
Socio-emotional & $115.5(20.1)$ \\
Adaptive behaviour & $82.1(12.2)$ \\
Recent (exposure $\leq 12$ months) & \\
Above threshold & $113(45 \%)$ \\
Below threshold & $140(55 \%)$ \\
Risk of alcohol use disorder (ASSIST) & \\
Low (<10) & $229(81 \%)$ \\
Moderate (11-26) & $35(12 \%)$ \\
High (> 26) & $19(6.7 \%)$ \\
\hline
\end{tabular}

Note: *mean (sd)

was 31 , with $50 \%$ of dyads having $\leq 5$ moments. The minimum duration of an SP moment was $0.5 \mathrm{~s}$ and the maximum $28 \mathrm{~s}$. The maximum aggregated duration for all SP moments was $133 \mathrm{~s}$. The median aggregated duration of SP moments [SP Sum] was $16 \mathrm{~s}$ (IQR: 3-36 s), with a median SP shortaverage of $3 \mathrm{~s}$ (IQR: $2-4 \mathrm{~s}$ ). The aggregated duration and frequency of SP moments are presented in Fig. 1.

\section{Mental health and other maternal factors}

Maternal age at birth, employment status, education, marital status and HIV status were associated with neither SP occurrence nor SP frequency (see Online Resource 1).

Unexpectedly, perinatal maternal depression was associated with a significantly greater number of shared positive moments (SP frequency) (ICC $=1.03[1.00-1.06], p=0.040)$. However, SP frequency appeared to be unrelated to EPDS among depressed mothers $(\mathrm{n}=103)(I C C=0.98[0.78-1.27]$, $p=0.893)$ and rather driven by mothers who were not depressed $(\mathrm{n}=179)(I C C=1.42[1.13-1.76], p=0.001)$. These findings were not further supported when looking at SP occurrence as the outcome $(p>0.05)$, and may then potentially be viewed as coincidental, especially given the absence of clinician-evaluated delineation between mothers who were clinically depressed relative to those who weren't.

There were no significant relationships between other perinatal maternal mental health factors and SP frequency or occurrence, including lifelong or recent exposure on the IPV, 
Fig. 1 Aggregated Frequency and Duration of SP moments

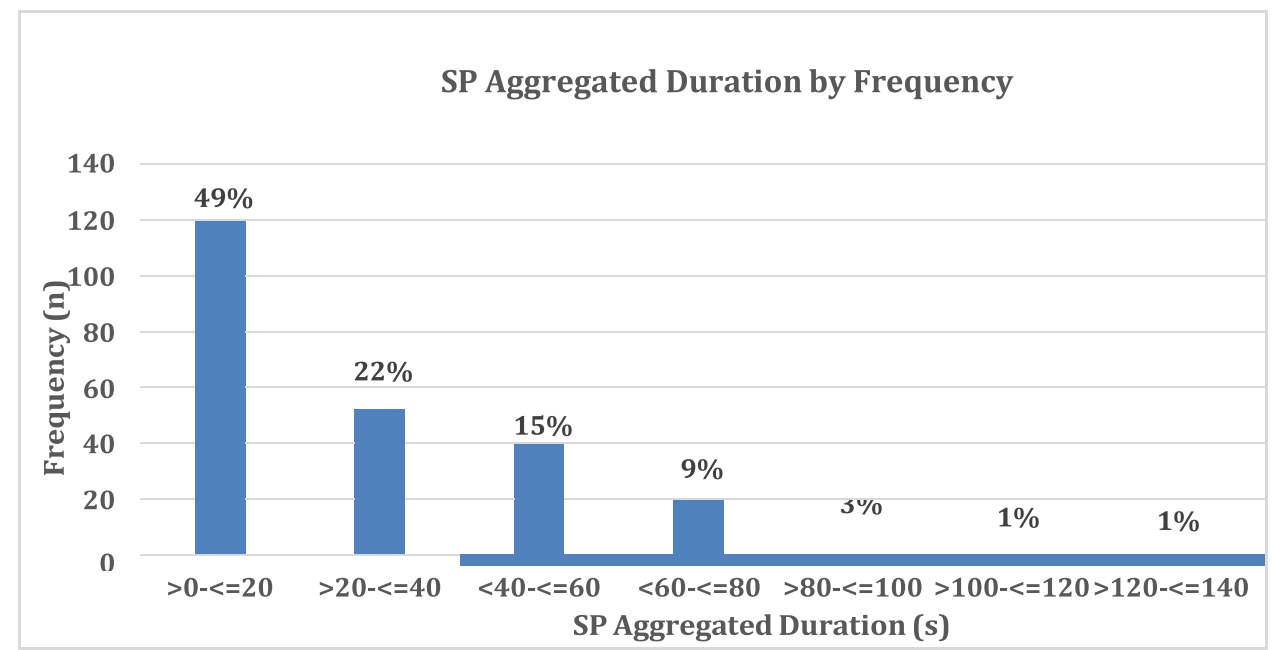

stressful life events (LEQ), psychological distress (SRQ-20) and risk of Alcohol Use Disorder (ASSIST).

\section{Infant birth and development}

Greater gestational age $(O R=1.45[1.10-1.93], p=0.008)$ and birth weight $(O R=1.50[1.12-2.02], p=0.006)$ were significantly associated with increased odds of SP occurrence. Furthermore, none of the infant development scales were associated with SP frequency or occurrence at age 24 months (see Online Resource 2).

\section{Sensitivity analysis findings}

Sensitivity analyses confirmed similar findings to those from main analyses (see Online Resource 3), greater gestational and birth ages significantly linked with a higher average SP duration, whereas greater risk for alcohol use disorder was significantly associated with a lower SP short-average duration [SP Short-average] (IRR $=0.90[0.76-1.06], p=0.027)$. However, a sub-analysis limited to mothers at risk for alcohol use disorder $(\mathrm{n}=54)$ appeared to dismiss this relation$\operatorname{ship}(I R R=0.97[0.76-1.22], p=0.768)$, likely reflecting an underpowered analysis.

\section{Discussion}

This study demonstrated 1) a high occurrence of positive interactional affectivity in a general population sample, 2) SP moments associated with higher age of gestation at delivery and infant birth weight, and 3) SP moments unrelated to maternal mental health or infant developmental outcomes in this cohort.

SP moments in this sample of $3 \frac{1}{2}$-month-old infant-andmother pairs were common (82\%). Transpiring SP moments were enduring (median aggregated length of $17 \mathrm{~s}$ ) and frequent, similar to previous SP studies (Latva et al. 2013; Puura et al. 2013). SP occurred in only $20.5 \%$ of dyads at 2 months (Lachman et al. 2021), but at 3 months infants typically took to their developmental milestones and spent more time smiling, specifically when gazing at their mothers (Messinger et al. 2001; Yale et al. 2003). So despite significant environmental stressors in our context (e.g. $84 \%$ unemployment rate), mothers could respond sensitively to and engage positively with their infants. The presence of SP moments was significantly associated with an older gestation age and higher birth weight at delivery. Previous SP studies have not fully explored these associations (Latva et al. 2013; Mäntymaa et al. 2015) and further work is needed to investigate the mechanisms which underlie these associations. The finding in our sample may be related to the neurotypical behaviour of full-term or closer- to-term infants during faceto-face interactions, characterised by typically "wide" smiles (Segal et al. 1995). An older (closer-to-term) gestational age may also foretell a better developed capacity for pro-social engagement in the first 2 years of life (Dueker et al. 2016). Underlying infant reactivity and self-regulation can furthermore affect infant ability to signal or seek out interaction with caregivers and depend on both temperamental vulnerabilites and caregiver sensitivity(Rothbart and Bates 2006).

Contrary to our hypothesis, SP moments were not associated with better maternal mental health or infant developmental outcomes in this cohort. Our findings contradict other studies linking maternal stressors and depressive symptoms with lower SP (Puura et al. 2019; Lachman et al. 2021). Although mothers with depressive symptoms can interact positively with their infants (Goodman and Gotlib 1999; Cornish et al. 2008). In prior work in the South African context, we found that SP was lower in mothers with severe mental illness (Lachman et al.2021). There are very few opportunities and tools available to sensitively 
and appropriately assess infant and maternal mental health in vulnerable populations, especially those in LMICs (Keller et al., 2018). Further work is needed to determine whether SP may be a culturally appropriate screen for mother-infant connectedness. It may therefore be a combination of risks rather than depression alone that determines adverse outcomes (Cornish et al. 2008). Increasingly, literature emphasises that even under adverse conditions, significant resilience may be evident (Ellis et al. 2017). Thus, for example mothers in this cohort also demonstrate remarkable resilience. Further work is, however, needed to assess SP in mothers with more severe mental illness.

Several limitations deserve emphasis. Firstly, this study did not consider a number of factors relevant to shared pleasure, including individual factors like maternal sensitivity and infant temperament. Secondly, it failed to measure a number of variables that impact synchronicity. Thirdly, the assessment of video content did not allow for implementation of computerised analysis methods and only moderate interrater agreement for mean duration of SP was found.

Taken together, our work indicates that despite mother-infant dyads facing risk factors for suboptimal development, there is frequent occurrence of positive SP moments in reciprocal dyadic interactions. Significant disruption in shared pleasure may be present only in extreme cases (e.g. mothers with severe mental disorders). Further work is needed to investigate the mechanisms underlying the associations between early mother-infant synchronicity and better outcomes noted here, and to assess whether SP may serve as a culturally appropriate screen for assessing connectedness.

Supplementary Information The online version contains supplementary material available at https://doi.org/10.1007/s00737-021-01199-0.

Acknowledgements Authors wish to acknowledge the support research staff of the Drakenstein Child Health Study.

Open Access This article is licensed under a Creative Commons Attribution 4.0 International License, which permits use, sharing, adaptation, distribution and reproduction in any medium or format, as long as you give appropriate credit to the original author(s) and the source, provide a link to the Creative Commons licence, and indicate if changes were made. The images or other third party material in this article are included in the article's Creative Commons licence, unless indicated otherwise in a credit line to the material. If material is not included in the article's Creative Commons licence and your intended use is not permitted by statutory regulation or exceeds the permitted use, you will need to obtain permission directly from the copyright holder. To view a copy of this licence, visit http://creativecommons.org/licenses/by/4.0/.

\section{References}

Bayley N (2006) Bayley scales of infant and toddler development, third edition: Technical manual. Harcourt, San Antonio
Beuenberg M, Orley JH, World Health Organization. Division of Mental Health (1994) A User's guide to the self reporting questionnaire (SRQ/compiled by M. Beusenberg and J. Orley). World Health Organization, Geneva

Brittain K, Myer L, Koen N, Koopowitz S, Donald KA, Barnett W, Zar HJ, Stein DJ (2015) Risk factors for antenatal depression and associations with infant birth outcomes: Results from a South African birth cohort study. Paediatr Perinat Epidemiol 29(505-514):420. https://doi.org/10.1111/ppe.12216

Brooks R, Meltzoff AN (2013) Gaze following: A mechanism for building social connections between infants and adults. In: Mikulincer M, Shaver PR (eds) Mechanisms of social connection: From brain to group. American Psychological Association, Washington, DC, pp 167-183

Christodoulou J, Rotheram-Borus MJ, Bradley AK, Tomlinson M (2019) Home visiting and antenatal depression affect the quality of mother and child interactions in South Africa. J Am Acad Child Adolesc Psychiatry 58:1165-1174. https://doi.org/10.1016/j.jaac. 2019.03.016

Cooper PJ, Landman M, Tomlinson M, Molteno C, Swartz L, Murray L (2002) Impact of a mother-infant intervention in an indigent peri-urban South African context: pilot study. Br J Psychiatry 180:76-81. https://doi.org/10.1192/bjp.180.1.76

Cornish AM, McMahon C, Ungerer JA (2008) Postnatal depression and the quality of mother-infant interactions during the second year of life. Aust J Psychol 60(142-151):434. https://doi.org/10. 1080/00049530701477738

Cox JL, Holden JM, Sagovsky R (1987) Detection of Postnatal Depression: Development of the 10-item Edinburgh Postnatal Depression scale. Br J Psychiatry 150(782-786):437. https://doi.org/10.1192/ bjp.150.6.782

Department of Health: RSA (2015) Ethics in Health Research Principles, Processes and Structures, 2nd edn. RSA, Pretoria, Department of Health. https://doi.org/10.5377/encuentro.v42i86.66

Donald KA, Hoogenhout M, du Plooy CP, Wedderburn CJ, Nhapi RT, Barnett W, Hoffman N, Malcolm-Smith S, Zar HJ, Stein DJ (2018) Drakenstein Child Health Study (DCHS): Investigating determinants of early child development and cognition. BMJ Paediatr Open 2:e00282. https://doi.org/10.1136/bmjpo-2018-000282

Donald KA, Wedderburn CJ, Barnett W, Nhapi RT, Rehman AM, Stadler JAM, Hoffman N, Koen N, Zar HJ, Stein DJ (2019) Risk and protective factors for child development: An observational South African birth cohort. PLoS Med 16:e1002920. https://doi. org/10.1371/journal.pmed.1002920

Dueker G, Chen J, Cowling C, Haskin B (2016) Early developmental outcomes predicted by gestational age from 35 to 41 weeks. Early Hum Dev 103(85-90):452. https://doi.org/10.1016/j.earlhumdev. 2016.07.006

Ellis BJ, Bianchi JM, Griskevicius V, Frankenhuis WE (2017) Beyond Risk and Protective Factors: An Adaptation-Based Approach to Resilience. Perspect Psychol Sci 12:561-455587. https://doi.org/ 10.1177/1745691617693054

Feldman R (2007) Parent-infant synchrony and the construction of shared timing; physiological precursors, developmental outcomes, and risk conditions. J Child Psychol Psychiatry 48:329-354. https://doi.org/10.1111/j.1469-7610.2006.01701.x

Feldman R, Greenbaum CW, Yirmiya N (1999) Mother-infant affect synchrony as an antecedent of the emergence of self-control. Dev Psychol 35:223-231. https://doi.org/10.1037/0012-1649.35.1.223

Fisher J, de Mello MC, Patel V, Rahman A, Tran T, Holton S, Holmes W (2012) Prevalence and determinants of common perinatal mental disorders in women in low-and lower- middle-income countries: a systematic review. Bull Orld Health Organ 90:139G-149G. https://doi.org/10.2471/BLT.11.091850

Goodman SH, Gotlib IH (1999) Risk for psychopathology in the children of depressed mothers: a developmental model for 
understanding mechanisms of transmission. Psychol Rev 106:458-490. https://doi.org/10.1037/0033-295x.106.3.458

Harpham T, Reichenheim M, Oser R, Thomas E, Hamid N, Jaswal S, Ludermir A, Aidoo M (2003) Measuring mental health in a costeffective manner. Health Policy Plan 18:344-349. https://doi.org/ 10.1093/heapol/czg041

Humeniuk R, Henry-Edwards S, Ali R, Poznyak V, Monteiro MGWHO (2010) The Alcohol, Smoking and Substance Involvement Screening Test (ASSIST): manual for use in primary care. World Health Organization, Geneva

Jewkes R (2002) Intimate partner violence: causes and prevention. Lancet 359:1423-1429. https://doi.org/10.1016/S0140-6736(02) 08357-5

Jewkes RK, Dunkle K, Nduna M, Shai N (2010) Intimate partner violence, relationship power inequity, and incidence of HIV infection in young women in South Africa: a 485cohort study. Lancet 376:41-48. https://doi.org/10.1016/s0140-6736(10)60548-x

Keller H, Bard K, Morelli G, Chaudhary N, Vicedo M, Rosabal-Coto M, Scheidecker G, Murray M, Gottlieb A (2018) The Myth of Universal Sensitive Responsiveness: Comment on Mesman et al. (2017). Child Dev 89:1921-1928. https://doi.org/10.1111/cdev. 13031

Kemppinen K, Kumpulainen K, Rasanen E, Moilanen I, Ebeling H, Hiltunen P, Kunelius A (2005) Mother-child interaction on video compared with infant observation: Is five minutes enough time for assessment? Infant Ment Health J 26:69-81. https://doi.org/ 10.1002/imhj.20031

Lachman, A., Niehaus, D. J. H., Jordaan, E. R., Leppanen, J., Puura, K., Bruwer, B. (2021) Shared Pleasure in early mother-infant interactions: a study in a high-risk South African sample. Early Child Dev Care 191:230-241 https://doi.org/10.1080/03004430. 2019.1613651

Latva R, Mäntymaa M, Puura K, Luoma I, Salmelin RK, Tamminen $\mathrm{T}$ (2013) Shared Pleasure in early infancy: building resilience? Tampere University.

le Roux S, Donald K, Brittain K, Phillips TK, Zerbe A, Nguyen KK et al (2018) Neurodevelopment of breastfed HIV-exposed uninfected and HIV-unexposed children in South Africa: a prospective cohort. AIDS 32:1781-1791. https://doi.org/10.1097/qad.00000 00000001872

Leclère C, Viaux S, Avril M, Achard C, Chetouani M, Missonnier S, Cohen D (2014) Why synchrony matters during mother-child interactions: a systematic review. PLoS ONE 9:e113571. https:// doi.org/10.1371/journal.pone.0113571

Maggi S, Irwin LJ, Siddiqi A, Hertzman C (2010) The social determinants of early child development: An overview. J Paediatr Child Health 46:627-635. https://doi.org/10.1111/j.1440-1754.2010. 01817.x

Mäntymaa M, Puura K, Luoma I, Latva R, Salmelin RK, Tamminen T (2015) Shared pleasure in early mother-infant interaction: Predicting lower levels of emotional and behavioral problems in the child and protecting against the influence of parental psychopathology. Infant Ment Health J 36:223-237. https://doi.org/10.1002/imhj. 21505

McHugh ML (2012) Interrater reliability: the kappa statistic. Biochem Med 22:276-282

Messinger DS, Fogel A, Dickson KL (2001) All smiles are positive, but some smiles are more positive than others. Dev Psychol 37:642-653

Murray L, Fiori-Cowley A, Hooper R, Cooper P (1996) The Impact of Postnatal Depression and Associated Adversity on Early MotherInfant Interactions and Later Infant Outcome. Child Dev 67:2512 2526. https://doi.org/10.1111/j.1467-8624.1996.tb01871.x

Myer L, Stein DJ, Grimsrud A, Seedat S, Williams DR (2008) Social determinants of psychological distress in a nationally-representative sample of South African adults. Soc Sci Med 66:1828-1840. https://doi.org/10.1016/j.socscimed. 2008.01.025

Patel V, Flisher AJ, Nikapota A, Malhotra S (2008) Promoting child and adolescent mental health in low and middle income countries. J Child Psychol Psychiatry 49:313-334. https://doi.org/10.1111/j. 1469-7610.2007.01824.x

Puura K, Davis H, Papadopoulou K, Tsiantis J, Ispanovic-Radojkovic V, Rudic N, Tamminen T, Turunen MM, Dragonas T, Paradisiotou A, Vizakou S, Roberts R, Cox A, Day C (2002) The European early promotion project: A new primary health care service to promote children's mental health. Infant Ment Health J 23(606624):534. https://doi.org/10.1002/imhj.10039

Puura K, Leppänen J, Salmelin R, Mäntymaa M, Luoma I, Latva R, Peltola M, Lehtimäki T, Tamminen T (2019) Maternal and infant characteristics connected to shared pleasure in dyadic interaction. Infant Ment Health J 40:459-478. https://doi.org/10.1002/imhj. 21786

Puura K, Mäntymaa M, Luoma I, Leppänen J, Peltola M, Latva R, Tamminen T (2013) Maternal and infant characteristics associated with shared pleasure in early mother-infant Interaction (PM-083). In 15th International Congress of ESCAP - EuropeanSociety for Child and Adolescent Psychiatry 6-10 July 2013, Dublin, Ireland. Eur Child Adolesc Psychiatry 22:87-313, ppS279-S280. https:// doi.org/10.1007/s00787-013-0423-9

Rademeyer V, Jacklin L (2013) A study to evaluate the performance of black South African urban infants on the Bayley Scales of Infant Development III. S Afr J Child Health 7:54-59. https://doi.org/ 10.7196/SAJCH.547

Ramsey MA, Gentzler AL (2015) An upward spiral: Bidirectional associations between positive affect and positive aspects of close relationships across the life span. Dev Rev 36:58-104. https://doi. org/10.1016/j.dr.2015.01.003

Richter LM, Daelmans B, Lombardi J, Heymann J, Boo FL, Behrman JR, Lu C, Lucas JE, Perez-Escamilla R, Dua T, Bhutta ZA, Stenberg K, Gertler P, Darmstadt GL (2017) Investing in the foundation of sustainable development: pathways to scale up for early childhood development. Lancet 389:103-118. https://doi. org/10.1016/S0140-6736(16)31698-1

Richter LM, Orkin FM, Adair LS, Kroker-Lobos MF, Mayol NL, Menezes AMB, Martorell R, Murray J, Stein AD, Victora C (2020) Differential influences of early growth and social factors on young children's cognitive performance in four low-and-middleincome birth cohorts (Brazil, Guatemala, Philippines, and South Africa). SSM Popul Health 12:100648. https://doi.org/10.1016/j. ssmph.2020.100648

Rothbart MK, Bates JE (2006) Temperament. In: Eisenberg N, Damon W, Lerner RM (eds) Handbook of child psychology, Social, emotional and personality Development, vol 3. John Wiley \& Sons Inc, New York, pp 105-176

Sallquist J, Eisenberg N, Spinrad TL, Gaertner BM, Eggum ND, Zhou N (2010) Mothers' and children's positive emo- tion: Relations and trajectories across four years. Soc Dev 19:799-821. https:// doi.org/10.1111/j.1467-9507.2009.00565.x

Segal LB, Oster H, Cohen M, Caspi B, Myers M, Brown D (1995) Smiling and Fussing in Seven-Month-Old Preterm and Full-Term Black Infants in the Still-Face Situation. Child Dev 66:1829-1843. https://doi.org/10.2307/1131913

Shamu S, Abrahams N, Temmerman M, Musekiwa A, Zarowsky C (2011) A systematic review of African studies on intimate partner violence against pregnant women: prevalence and risk factors. PLoS ONE 6:e17591. https://doi.org/10.1371/journal.pone.00175 91

Stein DJ, Koen N, Donald KA, Adnams CM, Koopowitz S, Lund C, Marais A, Myers B, Roos A, Sorsdahl K, Stern M, Tomlinson 
M, van der Westhuizen C, Vythilingum B, Myer L, Barnett W, Brittain K, Zar HJ (2015) Investigating the psychosocial determinants of child health in Africa: The Drakenstein Child Health Study. J Neurosci Methods 252:27-35. https://doi.org/10. 1016/j.jneumeth.2015.03.016

van der Westhuizen C, Wyatt G, Williams JK, Stein DJ, Sorsdahl K (2016) Validation of the Alcohol, Smoking and Substance Involvement Screening Test in a low- and middle- income country cross-sectional emergency centre study. Drug Alcohol Rev 35:702-709. https://doi.org/10.1111/dar.12424

Wachs TD, Black MM, Engle PL (2009) Maternal Depression: A Global Threat to Children's Health, Development, and Behavior and to Human Rights. Child Dev Perspect 3:51-59. https://doi. org/10.1111/j.1750-8606.2008.00077.x

WHO Assist Working Group (2002) The alcohol, smoking and substance involvement screening test (ASSIST): development, reliability and feasibility. Addiction 971183-4741194. https:// doi.org/10.1046/j.1360-0443.2002.00185.x

WHO, Unicef, World Bank Group (2018) Nurturing care for early childhood development: a framework for helping children survive and thrive to transform health and human potential. World Health Organization, Geneva

Yale ME, Messinger DS, Cobo-Lewis AB, Delgado CF (2003) The Temporal Coordination of Early Infant Communication. Dev Psychol 39:815-824. https://doi.org/10.1037/0012-1649.39.5.815

Zar HJ, Barnett W, Myer L, Stein DJ, Nicol MP (2015) Investigating the early-life determinants of illness in Africa: The Drakenstein Child Health Study. Thorax 70:592-594. https://doi.org/10.1136/ thoraxjnl-2014-206242

Publisher's Note Springer Nature remains neutral with regard to jurisdictional claims in published maps and institutional affiliations. 